\title{
AID TO LIBRARIES IN WAR AREAS
}

Up to the end of 1943 , more than $\$ 160,000$ has been spent for subscriptions to 325 scholarly and scientific journals, to be stored in this country, for distribution after the war to libraries in war areas. The money is provided by a grant from the Rockefeller Foundation, which has allotted from $\$ 50,000$ to $\$ 70,000$ annually for this purpose, since 1941.

Several factors influence orders placed for each title: the journal's foreign circulation before the war; the ratio of foreign circulation to total circulation; the number of free or exchange subscriptions; the number of copies available through gifts from subscribers in this country; and the relative importance of the journal to research.

In no case have purchases equalled more than half the number of paid institutional subscriptions in Europe and Asia discontinued because of the war. No funds are available for purchasing periodicals from individuals nor for the acquisition of volumes issued before 1939 .

The funds from the Rockefeller Foundation are administered by the Committee on Aid to Libraries in War Areas of the American Library Association. The committee's periodical purchases are supplemented by gifts. In this way current issues and back files of important periodicals have been secured for use in restocking libraries that have been damaged or destroyed. Anyone wishing to contribute mathematical journals for this purpose should address inquiries to Miss Edith A. Wright, Committee on Aid to Libraries in War Areas, Library of Congress Annex, Study 251, Washington, D. C. Prospective donors are asked to report titles and dates of the journals available to the office of the committee. Shipping instructions will then be issued, indicating where and how shipment should be made. 